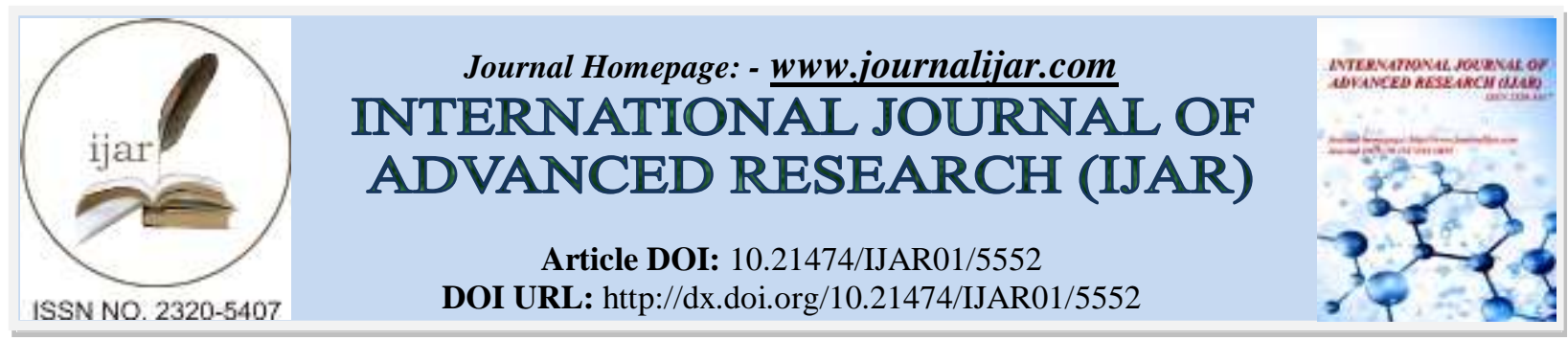

RESEARCH ARTICLE

\title{
IMMUNOHISTOCHEMICAL AND MORPHOMETRICAL STUDY OF GESTATIONAL INDUCED CHANGES IN MOUSE LIVER USING ANTI-ADIPONECTIN RECEPTOR 2.
}

\author{
Zahraa Fawzi A. Mohammed and May Fadhil AL-Habib. \\ Department of Human Anatomy, Section of Histology\& Embryology, University of AL-Nahrain, College of \\ Medicine, Baghdad, Iraq.
}

\section{Manuscript Info}

Manuscript History

Received: 06 August 2017

Final Accepted: 08 September 2017

Published: October 2017

Key words:-

Adiponectin receptor2, Liver,

Pregnancy, Immunohistochemical,

Hepatocytes.

\begin{abstract}
The liver is one of accessory organs associated with the digestive tract, it plays major role in carbohydrate and protein metabolism, inactivates many toxic substances and drugs, and synthesizes most plasma proteins and factors necessary for blood coagulation. The liver parenchyma represented by hepatocytes is adapted with the body changes in pregnancy. This study aimed to analyze the histomorphometrical changes in liver tissue and their cells in late pregnancy with special emphasis on the immunohistochemical reactivity of hepatocyte and their adaptation toward pregnancy changes using anti adiponectin receptor 2. The study design enrolled two groups; pregnant mice (15) in late gestational period and non pregnant mice (15); the liver tissues were collected and processed for paraffin block then sectioned, anti Adiponectin receptor $2 \mathrm{Ab}$ was used to demonstrate hepatocyte cells reactivity; quantitification of adiponectin receptor $2 \mathrm{Ab}$ reactivity done using Aperio Alogrithm soft ware. The present study was designed to assess the changes in the liver in different aspects. General morphological result showed changes of liver include increase in total body weight. Statistical analysis of the morphological changes recorded showed that the weight $1.611 \pm 0.061$ gram in control group and $2.255 \pm$ 0.043 gram of the pregnant group and the staining reactivity of antiAdiponectin receptor $2 \mathrm{Ab}$ in cells of liver in control group show high difference in positivity the mean was $(0.781 \pm 0.031$ pixel $/$ micron $)$, while weakly positive in pregnant group with mean $(0.180 \pm 0.006$ pixel/micron).

The study concluded that liver tissue adiponectin reactivity changes significantly with pregnancy.
\end{abstract}

Copy Right, IJAR, 2017,. All rights reserved.

\section{Introduction:-}

The liver is one of accessory organs associated with the digestive tract, it plays major role in carbohydrate and protein metabolism, inactivates many toxic substances and drugs, and synthesizes most plasma proteins and factors necessary for blood coagulation. The liver parenchyma represented by hepatocytes is adapted with the body changes in pregnancy. This study aimed to analyze the histomorphometrical changes in liver tissue and their cells in late pregnancy with special emphasis on the immunohistochemical reactivity of hepatocyte and their adaptation toward pregnancy changes using anti adiponectin receptor 2. The study design enrolled two groups; pregnant mice (15) in 
late gestational period and non pregnant mice (15); the liver tissues were collected and processed for paraffin block then sectioned, anti Adiponectin receptor $2 \mathrm{Ab}$ was used to demonstrate hepatocyte cells reactivity; quantitification of adiponectin receptor2 $\mathrm{Ab}$ reactivity done using Aperio Alogrithm soft ware. The present study was designed to assess the changes in the liver in different aspects. General morphological result showed changes of liver include increase in total body weight. Statistical analysis of the morphological changes recorded showed that the weight $1.611 \pm 0.061$ gram in control group and $2.255 \pm 0.043$ gram of the pregnant group and the staining reactivity of antiAdiponectin receptor $2 \mathrm{Ab}$ in cells of liver in control group show high difference in positivity the mean was $(0.781 \pm$ $0.031 \mathrm{pixel} / \mathrm{micron})$, while weakly positive in pregnant group with mean $(0.180 \pm 0.006 \mathrm{pixel} / \mathrm{micron})$.

The study concluded that liver tissue adiponectin reactivity changes significantly with pregnancy.

Pregnancy is a female pregnancy process of mammals one or more embryos in her body. ${ }^{(1)}$ In mice the pregnancy lasts about (20-22) days, the period of pregnancy in mice is divided into first, second and third weeks. The body including liver corresponds to pregnancy in form of special adaptive changes. ${ }^{(2)}$ The liver is the largest gland in the body of humans, vertebrates and other animals, its color is reddish to brown and contain four lobes of unequal size and shape in both human and mouse. ${ }^{(3)}$ The mouse liver consists of four major lobes with a variable lobation pattern. The fibrous capsule of the liver projects connective tissue septa into the liver tissue, dividing the liver lobes into indistinct lobules with the central vein, in the middle and at the corners the portal triad (consisting of branches of the hepatic artery, the portal vein, and the bile duct). ${ }^{(4)}$ Liver parenchyma consists of hepatocytes, large polygonal cells with large central nuclei, arranged in cords, in between the hepatocyte cords are sinusoids lined by fenestrated endothelium and Kuppfer cells which are liver- resident macrophages. The apical surfaces of adjacent hepatocytes form the bile canaliculated, which join to form bile ducts lined by cuboidal epithelium. ${ }^{(5)}$ Several studies that used mice as a model research on liver structures and functions assumed that there are wide similarities between the humans, mouse and rat liver. ${ }^{(6,7)}$ The liver has two main sources of blood, a hepatic portal vein and a hepatic artery. ${ }^{(8,9)}$ The pregnant woman experiences physiological changes to support fetal growth and development. In normal pregnancy, ultrasonographic examination reveals no dilatation of the biliary tract. The lithogenic or cholesterol saturation index of bile increases during pregnancy, which is considered as a cholelithogenic state. ${ }^{(10)}$ Adiponectin is a protein hormone that modulates a number of metabolic processes, including glucose regulation and fatty acid oxidation ${ }^{(11)}$. Adiponectin is exclusively secreted from adipose tissue (and also from the placenta in pregnancy into the blood stream and is very abundant in plasma relative to many hormones. ${ }^{(12)}$ Adiponectin binds to a number of receptors. So far, two receptors have been identified with homology to G protein-coupled receptors, and one receptor similar to the cadherin family :Adiponectin receptor 1 (AdipoR1), Adiponectin receptor 2 (AdipoR2) and T-cadherin - CDH13. ${ }^{(13)}$ In the liver the adiponectin its effects through a cell surface receptor system that depends on multiple proteins, AdipoR1 identified on the basis of its homology was highly in the liver specific Full-length adiponectin has a higher binding affinity to liver membrane fractions than globular adiponectin trimmers. ${ }^{(14)}$ Although the physiological role of adiponectin has not been fully established recent data have provided evidence that this hormone critically influences several components of the metabolic syndrome. ${ }^{(15)}$

\section{Materials and methods:-}

\section{Experimental animals and housing:-}

The current study was conducted on thirty mature female's albino mice Mus musculus collected from animal house in the AL-Nahrain University at 2016. The mice (body weight average between 20-30 gm and the age 8-10 weeks kept under conventional condition in acclimatized room with free access to water (fresh tap water) \& food (standard pellet diet) and maintained under a $12 \mathrm{~h}$ light $: 12 \mathrm{~h}$ darkness cycle and constant temperature $\left(22 \pm 2{ }^{\circ} \mathrm{C}\right)$. The mice were divided into two groups:

1-Group (A): Control group has 15 mature, non- pregnant female mice.

2-Group (B): Pregnant 15 female mice between 15-19 gestations.

Each one female mouse had been placed in cage with one healthy male mouse and checked each morning until vaginal plug was found. The first day of gestation was the day after the formation of vaginal plug.

\section{Sampling and tissue Preparation:-}

The animals were anasthesized with Ether; dissection was done to remove the liver under anesthesia and the animals were left to die by deep anesthesia. Under deep anesthetize the pregnant mice abdomen were disected and the liver separated and put in containers. The sample became ready for histological preparation of fixation, dehydration, clearing, paraffin embedding and sectioning dewaxing and hydration. All according to (Bancroft et al., 2013). ${ }^{(16)}$ 


\section{Immunohistochemistry:-}

The Super Sensitive IHC for Detection Kit (orb219874) Adiponectin Receptor 2 antibody (orb10047) Ag were found in liver cells by following all subsequent steps, which carried out at room temperature in a humidified chamber. Super Sensitive IHC Detection Kit (orb219874) was used. Sectioning at 4 $\mu$ were used and de-paraffinized, Incubate tissue in appropriate pretreatment or digestive enzyme for primary antibody, digestive enzyme use (pepsin enzyme); and PBS/TBS wash 3 times for 2 minutes. Then incubate slide in Hydrogen Peroxide Blocking Reagent for 10 minutes, PBS/TBS wash 3 times for 2 minutes. Apply Blocking Reagent and incubate for 5 minutes, PBS/TBS wash 3 times for 2 minutes (May be omitted if primary antibodies are diluted in buffers containing normal goat serum). Apply primary antibody and incubate according to manufacturer's recommended protocol (over night) incubation, PBS/TBS wash 3 times for 2 minutes. Apply HRP Polymer and incubate for 10 minutes, PBS/TBS wash 3 times for 2 minutes. Add 30 ul (1 drop) DAB Chromogen to $1 \mathrm{ml}$ of DAB Substrate, mix by swirling and apply to tissue. Incubate for about 3 - 5 minutes, PBS/TBS wash 3 times for 2 minutes. Finally counter stain and cover slip using a permanent mounting media.

\section{Statistical Analysis:-}

The Statistical Analysis System- SAS ${ }^{(17)}$ program was used to effect of difference factors in study parameters. T-test was used to significant compare between means and Chi-square test was used to significant compare between percentages in this study.

\section{Results:-}

Immunohistochemical IHC Study of Adiponectin receptor2 antibody orb 10047

Adiponectin receptor $2 \mathrm{Ab}$ was used to demonstrate adiponectin reactivity in liver hepatocyte and to quantify the differences of activity of those cells between the pregnant and control groups. Liver cells showed specific reaction with Adiponectin receptor $2 \mathrm{Ab}$ without any expression of other liver tissue. The expression of Adiponectin receptor $2 \mathrm{Ab}$ was seen mainly in the cell surface of hepatocytes and the staining reactivity was not observed in the nuclei of the hepatocyte cells. The nuclei component stained with counter stain -Harris Hematoxylin (Figure: 1A). In the aperio program observation the reaction between the anti adiponectin receptor $2 \mathrm{Ab}$ and liver cells was represented by different degrees of the strength of positivity of Anti Adiponectin receptor 2 Ab (Figure: 1B). The reaction was homogenous in cell membrane of liver hepatocytes, the observation of results reaction yellowish to brownish in color and seems to be more in control group than in those in pregnant group. (Figure: 2A\& 2B). In the aperio program observation the reaction was high positivity represented in dark brown color (Figure: 2C\& 2D).

Cell membrane of hepatocytes showed an intense reactivity toword adiponectin receptor 2 Ab chromogen, the reaction was ranging between positive and strong positive reaction in control group (Figure: 2). The intensity of this reaction in control group, made the appearance of other structure easily identified like liver sinusoid and bile caniliculi, but identification between there was not possible (Figure: 2). In pregnant group the picture different the reaction intensity was very weak ranged between negative and weak positive and it was not possible to identify the cell margins of hepatocyte (Figure: 3 A,B,C and D).

The degree of positivity measured by using aperio program and this program showed different color in regards to the intensity of the reaction:

- The strong positivity appears in a brown color.

- The positivity appears in orange color.

- The weak positivtiy appears in yellow color.

- $\quad$ The negative appear in blue color.

- The white colors indicate no tissue in the sections. 

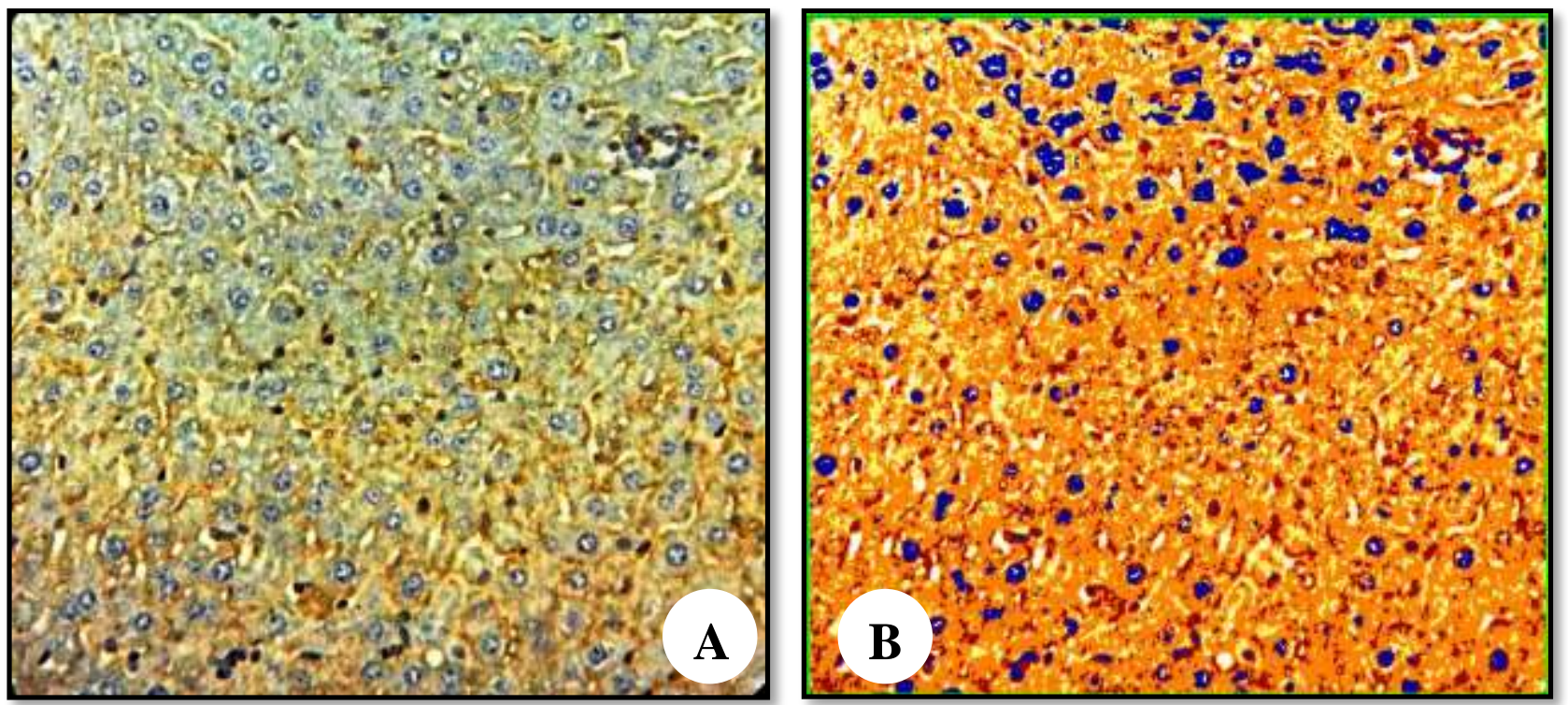

(Figure: 1) A: Section in the liver show the hepatocytes of control group high detection of anti Adiponectin with $\mathrm{NO}$ expression of anti Adiponectin in the nucleus with clear nucleolus. Anti Adiponectin receptor $2 \mathrm{Ab}$, control group, X20.B: Section in the liver in aperio program show the positivity reaction represented in brown color, weak positive represented in yellow color and negative represented in blue color. Anti Adiponectin receptor $2 \mathrm{Ab}$, control group, X20.
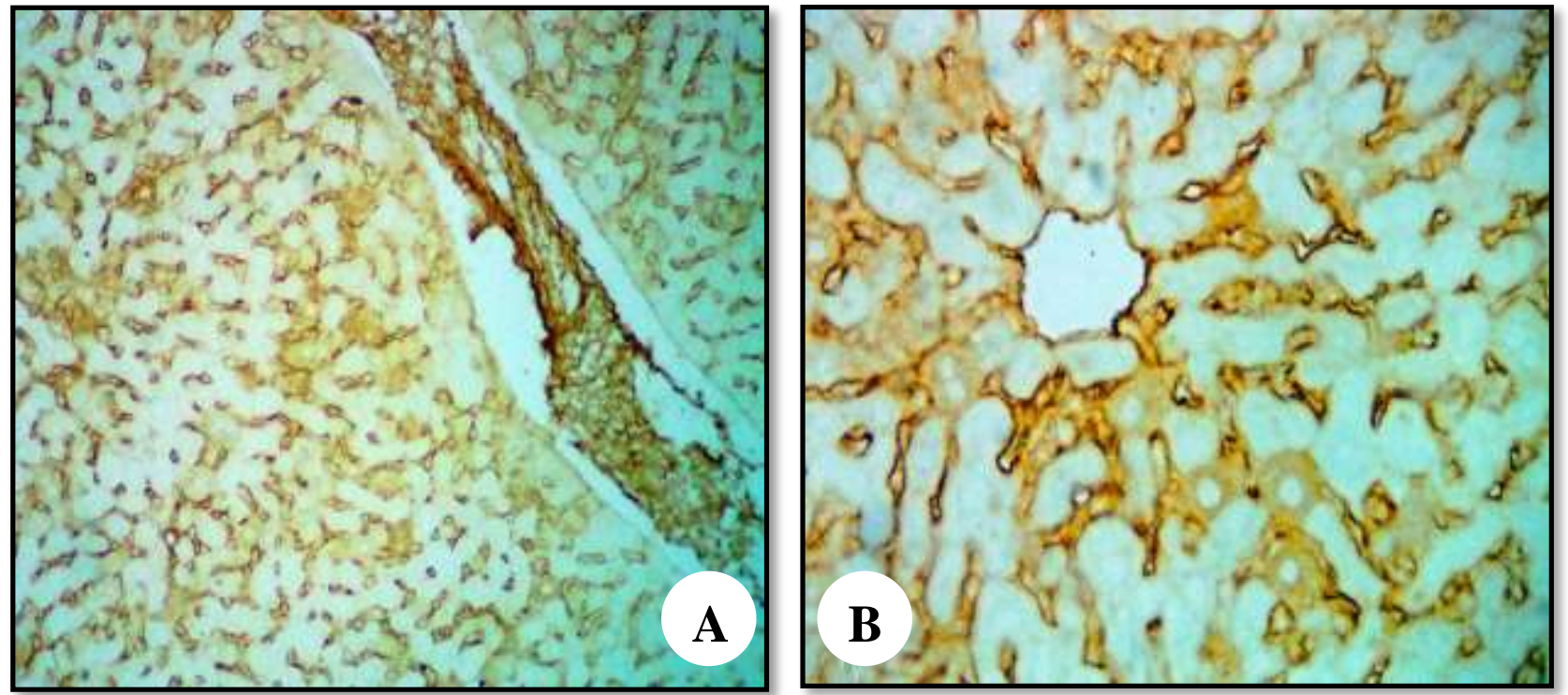

(Figure: 2) A, B: Sections in the liver show the hepatocytes of control group high detection of anti Adiponectin found in the cell surface (strong positive) in the cell membrane. A: control group, X20, B: X 40. 

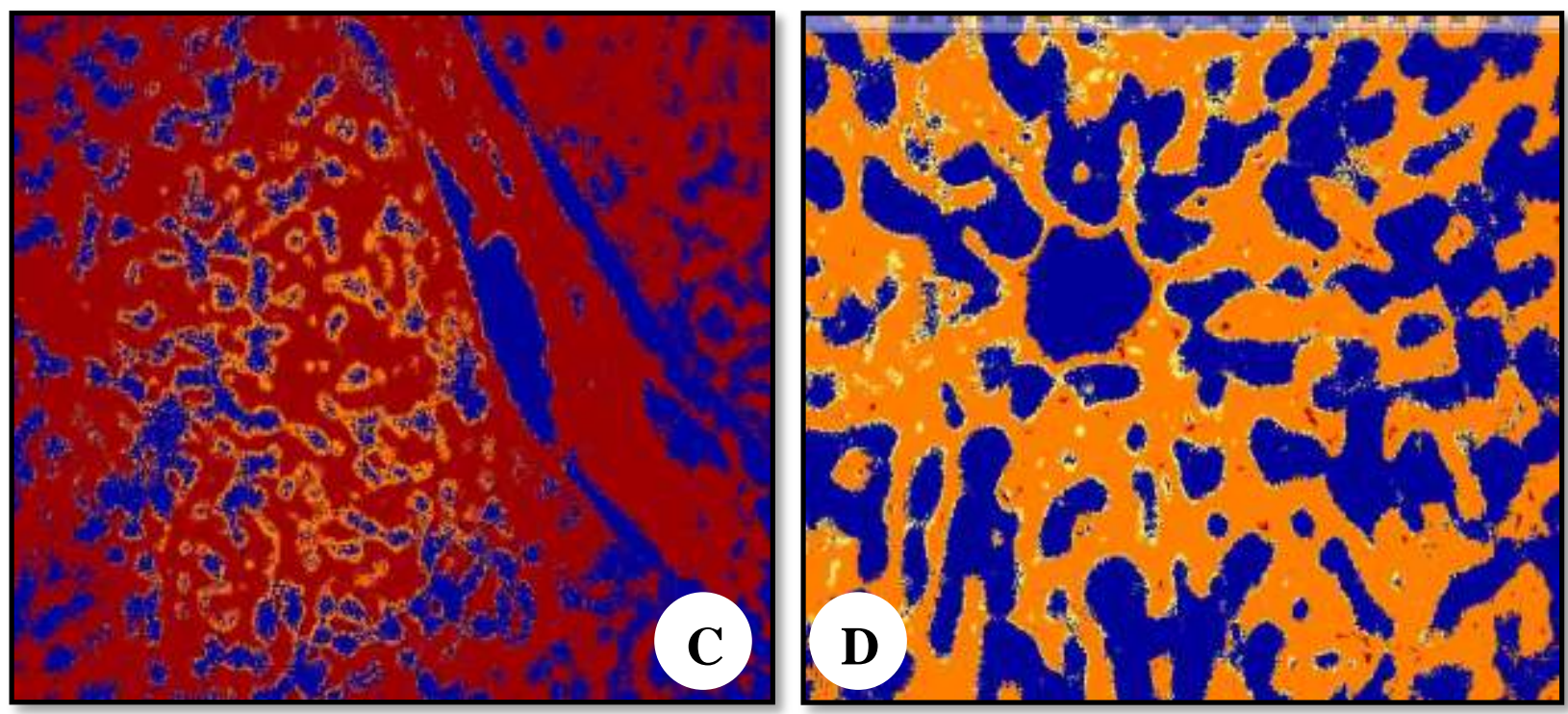

(Figure: 2) C, D: Section in the liver after inserts the previous image in aperio program show the high positivity reaction represented in dark brown color. Anti Adiponectin receptor 2 Ab, control group, B: X20, D: X40.
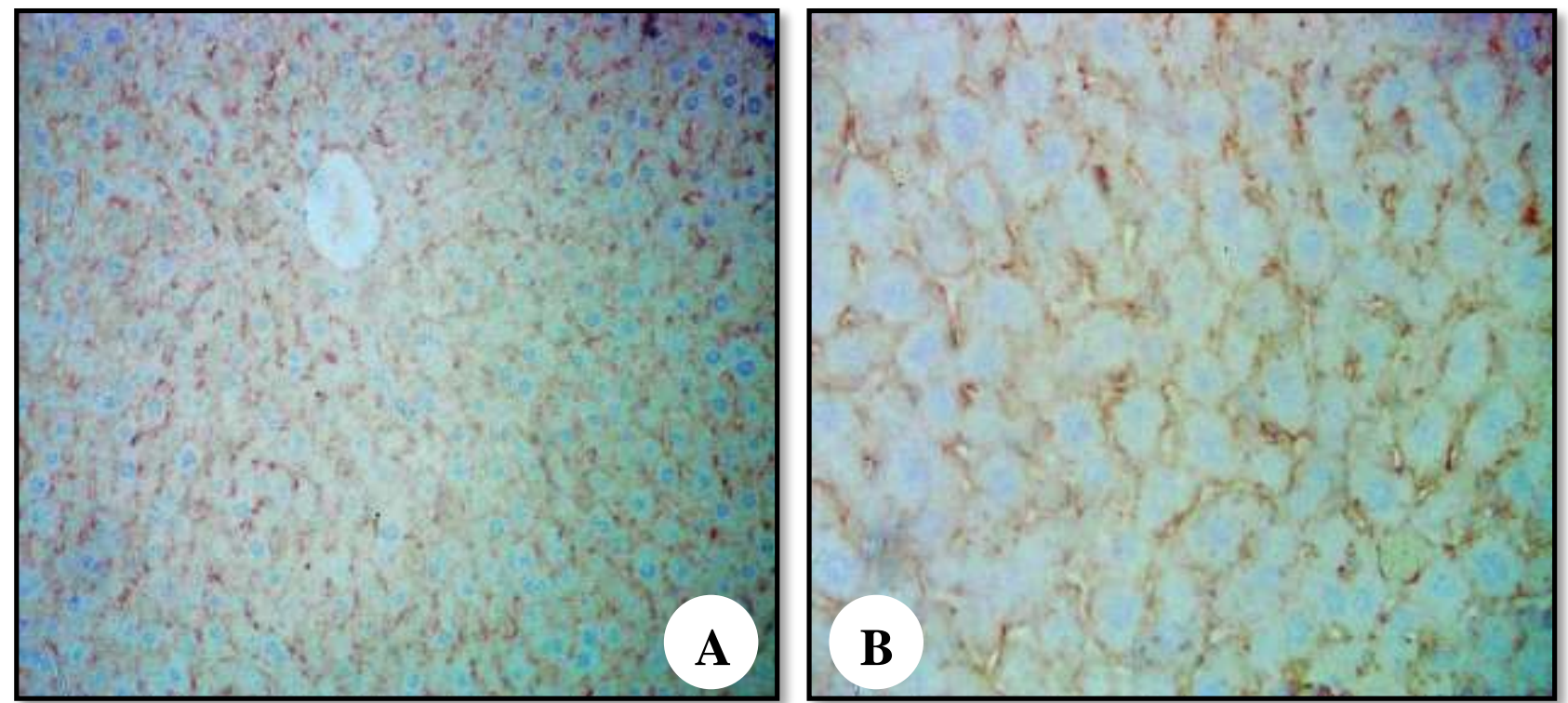

(Figure: 3) A, B: Sections in the liver show the hepatocytes of control group high detection of anti Adiponectin found in the cell membrane. pregnant group, A: X20, B: X 40. 

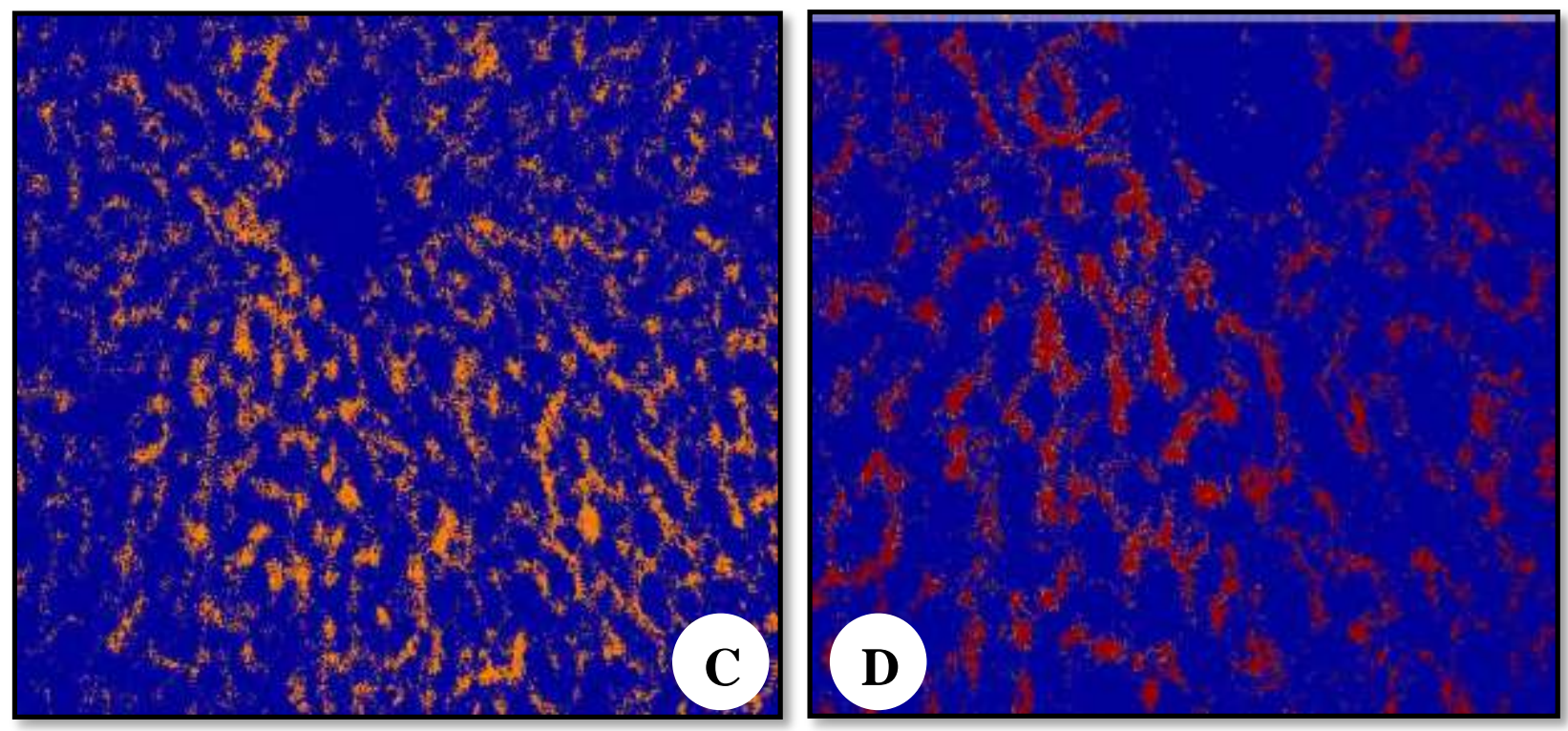

(Figure: 3) C, D: Section in the liver after inserts the previous image in aperio program show the low positivity reaction represented in brown color. Anti Adiponectin receptor 2 Ab, pregnant group, C: X20, D: X40.

\section{Morphometrical Analysis of Immunohistochemical Reactivity of Adiponectin receptor 2 Ab:}

The staining reactivity of adiponectin receptor $2 \mathrm{Ab}$ was represented by calculating the mean positivity percentage in the paraffin sections for both pregnant and control (non-pregnant) groups; the staining reactivity was high in control group than those in pregnant group. The staining reactivity of anti- Adiponectin receptor $2 \mathrm{Ab}$ in cells of liver in control group show high difference in positivity. There was strong positive reactivity in cell membrane of hepatocyte in control group. On the other hand, the reactivity in cell membrane of hepatocyte that is weakly positive in pregnant group. Table [1] \& (Figure: 4).

Table 1:- Show the difference Strength of positivity of Anti Adiponectin receptor $2 \mathrm{Ab}$ of liver cells in control and pregnant groups.

\begin{tabular}{|l|l|}
\hline The Group & $\begin{array}{l}\text { Mean } \pm \text { SE of } \\
\text { Adiponectin pixel/micron }\end{array}$ \\
\hline Control & $0.781 \pm 0.031$ \\
\hline Pregnant & $0.180 \pm 0.006$ \\
\hline P-value & 0.0001 \\
\hline \multicolumn{2}{|c|}{$* *(\mathrm{P}<0.01)}$. \\
\hline
\end{tabular}

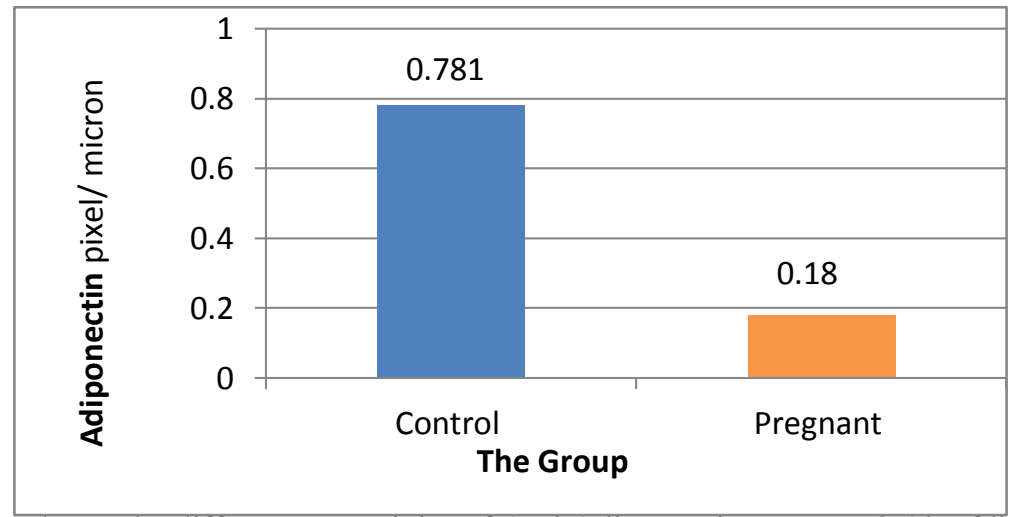

(Figure: 4): Histogram shows the difference reactivity of Anti Adiponectin receptor $2 \mathrm{Ab}$ of liver cells in control and pregnant groups. 


\section{Discussion:-}

Adiponectin receptor $2 \mathrm{Ab}$ is an adipokine that has anti-diabetic, anti-atherogenic, anti-inflammatory and angiogenic properties it is a hormone produce by adipocytes and there receptor and the situated of surface many types of cells including hepatocytes two receptors aggregation adiopnectin receptor 2 in the present of cell surface of hepatocytes these are adiponectin receptor $1 \&$ adiponectin receptor $2^{(18)}$, this study to assess the liver expression of adiponectin receptor 2 in pregnant and correlation of quantification of adiponectin with the non-pregnant group. Pregnancy needs to meets the energy requirements by the development of fetus this intern need aspecial dynamic rearrangements of adipose tissue activity which is usually associated with an initial period of adipogenesis followed by increase lipolytic activity ${ }^{(19)}$, the present study showed that quantitative expression of adiponectin receptor 2 in adipocytes was less than those recorded a non pregnant (control group) and this result respond to be in approval with many other studies than by different authers that discripe changes of adiponectin during pregnancy and showed the progressive decline of plasma adiponectin that in pregnancy advanced. ${ }^{(20,21,22)}$ Opposite it to the non-pregnant state adiponectin level so out pregnancy it is not correlated to maternal body mass index, however there is the distraction of the correlation between the adiponectin and maternal weight can results were form several factors the most appaling cause for this description this dramtic for hormonal changes during pregnancy total body weight showed $(33.15 \pm 0.57 \mathrm{~g})$ in pregnant group and $(29.08 \pm 0.55 \mathrm{~g})$ non-pregnant group in a study done by ${ }^{(23)}$, basic metabolic was study investigated in for hand pregnant women in relation in the pregnancy trimesters. Maternal characteristics of plasma adiponectin consentration showed a significant decrease in the level of serum adiponectin with the advanced pregnancy gestational age and the increase body mass index the over all analysis of level of adiponectin in pregnant and non-pregnant group showed a slightly statistical significant decrease in level of plasma adiponectin concentration with advancing gestational age but significant difference between in the three trimesters were not found. ${ }^{(24,23)}$

Most of the literature regarding maternal adiponectin level was confind to plasma level concentration very few were found to investigate tissue expression of adiponectin during pregnancy the adiponectin is negatively correlated with homeostatic model assessment insulin resistance (HOMA-IR) and a decrease in maternal adiponectin after delivery indicates a significant placental contribution to adiponectin production. In addition, adiponectin levels correlate with whole body insulin sensitivity, because of the insulin sensitizing effects of adiponectin in muscle and liver, adiponectin reduces hepatic glucose production and enhances insulin action in the liver and peripheral utilization of glucose. ${ }^{(25)}$ The marked increase of circulating adiponectin with relatively little benefit in people with T1D indicates a breakdown of the adiponectin signaling pathway. In nonobese diabetic (NOD) mice, an autoimmune model of $\mathrm{T} 1 \mathrm{D}$, the loss of adiponectin signaling in the liver is evident from the reduction of SOGA, Insulin injection eliminates hyperglycemia in NOD mice without correcting the deficiency of SOGA. TZD drugs currently prescribed for the treatment of insulin resistance in T1D may work by stimulating the production of adiponectin and SOGA. However, considering the breakdown of the adiponectin signaling pathway in T1D, the development of medications that stimulate the production of SOGA directly could restore the metabolic balance, diminish the insulin requirement and improve clinical outcomes. ${ }^{(21)}$

The parallel changes in total plasma adiponectin and adipose tissue adiponectin gene expression argue in favour of plasma adiponectin levels reflecting pregnancy-associated adiponectin production. Whether the regulation is at the transcriptional or translational level or at the level of secretion into the systemic circulation is not known. Very few data are available concerning the transcriptional regulation of the adiponectin gene. A c/EBP- $\alpha$ consensus binding site has been found in the first intron of the gene but functional significance for regulation is not yet established Glucocorticoids, TNF- $\alpha$ or IL-6 are putative negative regulatory factors of the adiponectin gene whereas insulinmediated regulation has not been documented. This may be surprising in view of the observation that insulin is able to suppress the concentra tion of plasma adiponectin. ${ }^{(26.27)}$ Different adiponectin oligomers activate different transduction pathways and, this may account for regulating the bioactivity of adiponectin in relation to insulin action. The loss of insulin effect on adiponectin expression during pregnancy compared with the non-gravid state indicates impairment with insulin action in white adipose tissue, the main site of adiponectin production. This may result from increased levels of insulin antagonists because there is no apparent intrinsic defect of insulin receptor activity in adipocytes from pregnant women. ${ }^{(28)}$

Immunohistochemical study for adiponectin and adiponectin receptor 2 was performed in liver biopsies and the adiponectin expression was formed to be more intencity localized in hepatocytes near by endotheial cells of liver sinusoid or near by portal vessels adiponectin staining reactivity was less pronounced in endothelial cell of liver sinusoid while hepatocyte showed predominant staining pattern. ${ }^{(29)}$ Adiponectin are one was found to be more 
localization with endothelial cells of portal vessels in liver sinusoid while adiponectin receptor 2 was exclusively detection in hepatocytes this many suggested that this hormonal receptor have could function in a paracrine way in the liver as the majority $(\sim 80 \%)$ of blood flow to the liver is delivered via the portal vein and adiponectin secretion is lower from visceral than subcutaneous fat it is likely that systemic plasma adiponectin concentrations do not accurately reflect the delivery of adiponectin to the liver. The purpose of the present study was therefore to evaluate the relationship between the delivery of adiponectin to the liver and hepatic glucose and lipoprotein metabolism. Portal vein and radial artery plasma adiponectin concentrations, hepatic glucose production rate, and hepatic VLDLTG and VLDL- apoB-100 secretion rates were determined in subjects with extreme obesity, who had large amounts of visceral fat. We hypothesized that portal vein adiponectin concentration would be inversely correlated with hepatic glucose and lipoprotein production. ${ }^{(30)}$

Adiponectin is the most abundant secretory protein produced by adipose tissue. Although plasma concentrations of most adipocyte hormones increase with increasing adiposity, adipose tissue adiponectin gene expression and plasma concentration decrease with increased body fat and increase after weight loss adiponectin gene expression is similar in subcutaneous upper and lower body fat depots but is lower in visceral than in subcutaneous adipose tissue, adiponectin secretion from subcutaneous and especially visceral fat is reduced with increasing adiposity. ${ }^{(31)}$ Low plasma adiponectin concentrations are associated with several obesity-related metabolic abnormalities, including increased fasting plasma glucose, total plasma triglyceride (TG), very low-density lipoprotein (VLDL)-TG, and VLDL- apolipoprotein B-100 (apoB-100) concentrations. These data suggest that adiponectin influences liver metabolism because basal hepatic glucose and VLDL production are important determinants of plasma glucose and TG concentrations. Moreover, data from studies conducted in animal models and in isolated human hepatocytes demonstrate that adiponectin is directly involved in the regulation of hepatic glucose and lipid metabolism. Adiponectin decreases postabsorptive hepatic glucose output, stimulates hepatic fatty acid oxidation, suppresses the expression of enzymes involved in hepatic gluconeogenesis and lipogenesis, lowers hepatocyte apoB-100 messenger RNA, inhibits apoB-100 release, and reduces intrahepatic TG content. ${ }^{(32)}$

\section{Conclusion:-}

In conclusion, Adiponectin receptor $2 \mathrm{Ab}$ reactions in the surface of hepatocyte and have low reactivity in late pregnancy compare with non pregnant group. The adiponectin receptor 2 was specific expressed in hepatocyte surface with out other than.

\section{Acknowledgment:-}

I would like to express my sincere gratitude to my supervisor Prof. Dr. May F. Al-Habib for her suggestion this work, her patience, great support, generous help and continuous guidance throughout the course of study. I would like to thank all the members of the department of Human Anatomy, Histology \& Embryology at the College of Medicine /Al-Nahrarain University for their kind help and support.

\section{References:-}

1. Arm, F., Oinuma, M., \& Clak, S. I. (2011). Rethinking the definition of "Term Pregnancy". Obstetric Anesthesia Digest, 31(3), 144-145.

2. Suckow, M. A., Danneman, P., \& Brayton, C. (2001). The laboratory mouse. CRC Press LLC.

3. Junqueira, L. C., Mescher, A. L \& Carneiro, J. (2013). Basic histologytext and atlas. London: McGraw Hill, 65$85,287-297$.

4. Tortora, G. J., \& Derrickson, B. H. (2008). Principles of anatomy and physiology. John Wiley \& Sons.

5. Conti, C. J., Jimenez Conti, I. B., Benavides, F., FRIJHOFF, A., \& Conti, M. A. (2004). Atlas of laboratory mouse histology. National Institute of Allergy and Infectious Diseases, National Institutes of Health, Bethesda, Maryland ACVP, American College of Veterinary Pathologists.

6. Robertson, R. T., Baratta, J. L., Haynes, S. M., \& Longmuir, K. J. (2008). Liposomes incorporating a Plasmodium amino acid sequence target heparan sulfate binding sites in liver. Journal of pharmaceutical sciences, 97(8), 3257-3273.

7. Longmuir, K. J., Robertson, R. T., Haynes, S. M., Baratta, J. L., \& Waring, A. J. (2006). Effective targeting of liposomes to liver and hepatocytes in vivo by incorporation of a Plasmodium amino acid sequence. Pharmaceutical research, 23(4), 759-769.

8. Agur, A. M., \& Dalley, A. F. (2009). Grant's atlas of anatomy. Lippincott Williams \& Wilkins. 
9. Pannarale, L., Onori, P., Borghese, F., Conte, D., \& Gaudio, E. (2006). Three-dimensional organization of the hepatic artery terminal branches: a scanning electron microscopic study of vascular corrosion casts of rat liver. Italian journal of anatomy and embryology= Archivio italiano di anatomia ed embriologia, 112(1), 1-12.

10. Everson, G. T. (1998). Liver problems in pregnancy: distinguishing normal from abnormal hepatic changes. Medscape women's health, 3(2), 3-3.

11. Diez, J. J., \& Iglesias, P. (2003). The role of the novel adipocyte-derived hormone adiponectin in human disease. European Journal of endocrinology, 148(3), 293-300.

12. Chen, J., Tan, B., Karteris, E., Zervou, S., Digby, J., Hillhouse, E. W., \& Randeva, H. S. (2006). Secretion of adiponectin by human placenta: differential modulation of adiponectin and its receptors by cytokines. Diabetologia, 49(6), 1292.

13. Hug, C., Wang, J., Ahmad, N. S., Bogan, J. S., Tsao, T. S., \& Lodish, H. F. (2004). T-cadherin is a receptor for hexameric and high-molecular-weight forms of Acrp30/adiponectin. Proceedings of the National Academy of Sciences of the United States of America, 101(28), 10308-10313.

14. Mao, X., Kikani, C. K., Riojas, R. A., Langlais, P., Wang, L., Ramos, F. J., .. \& Liu, F. (2006). APPL1 binds to adiponectin receptors and mediates adiponectin signalling and function. Nature cell biology, 8(5), 516.

15. Tietge, U. J., Böker, K. H., Manns, M. P., \& Bahr, M. J. (2004). Elevated circulating adiponectin levels in liver cirrhosis are associated with reduced liver function and altered hepatic hemodynamics. American Journal of Physiology-Endocrinology and Metabolism, 287(1), E82-E89.

16. Bancroft, J. D., Floyd, A. D., \& Suvarna, S. K. (2013). Bancroft's Theory and Practice of Histological Techniques,53, 83, 93, 105-121, 433-517.

17. Statistical Analysis System, User's Guide. Statistical SAS. (2014). Version $9.1^{\text {th }}$ ed. SAS. Inst. Inc. Cary. N.C. USA.

18. Nannipieri, M., Cecchetti, F., Anselmino, M., Mancini, E., Marchetti, G., Bonotti, A., ... \& Santini, F. (2009). Pattern of expression of adiponectin receptors in human liver and its relation to nonalcoholic steatohepatitis. Obesity surgery, 19(4), 467.

19. Herrera, E. (2002). Lipid metabolism in pregnancy and its consequences in the fetus and newborn. Endocrine, 19(1), 43-55.

20. Fuglsang, J., Skjaerbaek, C., Frystyk, J., Flyvbjerg, A., \& Ovesen, P. (2006). A longitudinal study of serum adiponectin during normal pregnancy. BJOG: An International Journal of Obstetrics \& Gynaecology, 113(1), 110-113.

21. Combs, T. P., \& Marliss, E. B. (2014). Adiponectin signaling in the liver. Reviews in Endocrine and Metabolic Disorders, 15(2), 137-147.

22. Blaslov, K., Bulum, T., Zibar, K., \& Duvnjak, L. (2013). Relationship between adiponectin level, insulin sensitivity, and metabolic syndrome in type 1 diabetic patients. International journal of endocrinology, 2013.

23. Nien, J. K., Mazaki-Tovi, S., Romero, R., Erez, O., Kusanovic, J. P., Gotsch, F., ... \& Espinoza, J. (2007). Plasma adiponectin concentrations in non-pregnant, normal and overweight pregnant women. Journal of perinatal medicine, 35(6), 522-531.

24. Mazaki-Tovi, S., Kanety, H., \& Sivan, E. (2005). Adiponectin and human pregnancy. Current diabetes reports, 5(4), 278-281.

25. Vitoratos, N., Deliveliotou, A., Vlahos, N. F., Mastorakos, G., Papadias, K., Botsis, D., \& Creatsas, G. K. (2008). Serum adiponectin during pregnancy and postpartum in women with gestational diabetes and normal controls. Gynecological Endocrinology, 24(11), 614-619.

26. Thamer, C., Machann, J., Tschritter, O., Haap, M., Wietek, B., Dahl, D., ... \& Schick, F. (2002). Relationship between serum adiponectin concentration and intramyocellular lipid stores in humans. Hormone and metabolic research, 34(11/12), 646-649.

27. Stefan, N., Vozarova, B., Funahashi, T., Matsuzawa, Y., Ravussin, E., Weyer, C., \& Tataranni, P. A. (2002). Plasma adiponectin levels are not associated with fat oxidation in humans. Obesity, 10(10), 1016-1020.

28. Bruce, C., Bumby, J., Mangnall, D., \& Fraser, R. B. (1992). Evidence that the insulin resistance of pregnancy may not involve a post-receptor defect in human adipocytes. Diabetes research and clinical practice, 16(2), 7584.

29. Kaser, S., Moschen, A., Cayon, A., Kaser, A., Crespo, J., Pons-Romero, F., \& Tilg, H. (2005). Adiponectin and its receptors in non-alcoholic steatohepatitis. Gut, 54(1), 117-121.

30. Magkos, F., Fabbrini, E., Patterson, B. W., Eagon, J. C., \& Klein, S. (2011). Portal vein and systemic adiponectin concentrations are closely linked with hepatic glucose and lipoprotein kinetics in extremely obese subjects. Metabolism, 60(11), 1641-1648. 
31. Fain, J. N., Madan, A. K., Hiler, M. L., Cheema, P., \& Bahouth, S. W. (2004). Comparison of the release of adipokines by adipose tissue, adipose tissue matrix, and adipocytes from visceral and subcutaneous abdominal adipose tissues of obese humans. Endocrinology, 145(5), 2273-2282.

32. Asterholm, I. W., \& Scherer, P. E. (2010). Enhanced metabolic flexibility associated with elevated adiponectin levels. The American journal of pathology, 176(3), 1364-1376. 